\title{
Diode-Pumped Alexandrite Laser - a new prospect for Remote Sensing
}

\author{
Michael Damzen*, Gabrielle Thomas*, Achaya Teppitaksak*, Emma Arbabzadah*, William \\ Kerridge-Johns*, and Ara Minassian** \\ * Photonics Group, Imperial College London, London SW7 2AZ, UK \\ ** Unilase Ltd, London, UK
}

\begin{abstract}
Tunable-wavelength diode-pumped Alexandrite laser operation includes highest power $>26 \mathrm{~W}$ (end-pumped rod); $>12 \mathrm{~W}$ (side-pumped slab); and first Q-switched operation with pulse energy $\sim 1 \mathrm{~mJ}$ at $\mathrm{kHz}$ repetition rate, as development for space lidar application.
\end{abstract}

\section{INTRODUCTION}

There is a broad class of vibronic lasers based on chromium $\left(\mathrm{Cr}^{3+}\right)$ doped solid-state crystals. Key scientific motivations for their development is their impressive wavelength tunability range across the important near-IR wavelength region $(\sim 700-1100 \mathrm{~nm})$; bandwidth allowing laser operation with femtosecond pulse duration (10fs, in principle); and broad absorption bands that can be efficiently pumped by red diode laser $(A l G a \operatorname{InP})$ technology. Of special interest is Alexandrite $\left(\mathrm{Cr}^{3+}\right.$-doped Chrysoberyl) that has additional exceptional laser properties that makes this material the focus of this investigation. Alexandrite has very high thermal conductivity $23 \mathrm{~W} / \mathrm{mK}$ (twice that of 'industry-standard' laser crystal Nd:YAG), long upper state lifetime $262 \mu \mathrm{s}$ (two orders of magnitude higher than 'scientific-standard' titanium-doped sapphire laser), and extraordinarily high mechanical strength and high optical damage threshold [1]. Together these properties hold the opportunity for exceptionally high power and high energy pulse operation with tunability in an important waveband. However, to-date very limited work has been done on diode-pumped Alexandrite. In this presentation, we review our work on diode-pumped Alexandrite in rod and slab formats; power $>26 \mathrm{~W}$, two-orders of magnitude higher than prior diode-pumped Alexandrite work; high efficiency fibre-delivered red diode pumping $(>1 \mathrm{~W} ; 42 \%$ slope efficiency; $\left.T E M_{00} M^{2} \sim 1.05\right)$. We demonstrate the first-ever Q-switched operation with $\mathrm{mJ}$ pulses at $\mathrm{kHz}$ pulse rate as a development to address space lidar applications [2]. The issues of temperature tuning the lasing properties and excited state absorption are also investigated and discussed.

\section{DIODE END-PUMPED ALEXANDRITE LASER SYSTEMS}

Diode-end pumped Alexandrite rods were investigated with fibre and free space delivery of red diode modules at $\sim 636 \mathrm{~nm}$. The rods had length $10 \mathrm{~mm}$ and diameter $4 \mathrm{~mm}$ : one with 0.13 at.\% and the other with 0.22 at.\% Crdoping. The end faces of the rods were plane-parallel and anti-reflection coated at the Alexandrite wavelength $(\sim 755 \mathrm{~nm})$.

\section{A. Fibre-delivered red diode end-pumping system}

The fibre-delivered system design is shown in Fig. 1, using both a simple compact laser cavity design and an extended design with birefringent tuner.

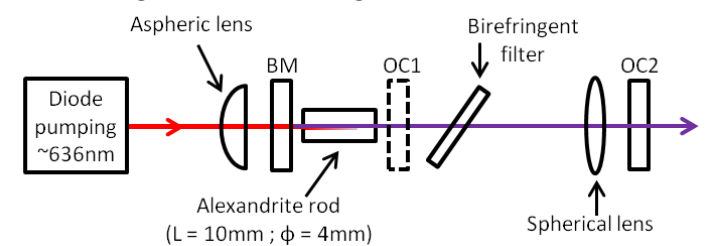

Fig. 1. Fibre-delivered red diode end-pumping Alexandrite rod laser in a) compact cavity (output coupler OC1), and b) extended and wavelength tuned cavity with $\mathrm{OC} 2$. BM is dichroic back mirror, HR at $755 \mathrm{~nm}$; HT at $636 \mathrm{~nm}$ pump wavelength

In the compact design, the output power against pump power is shown in Fig.2. Output power $1.08 \mathrm{~W}$ was achieved at $3 \mathrm{~W}$ pump power, at $\sim 760 \mathrm{~nm}$, with spatial beam quality $\mathrm{TEM}_{00}$ with $\mathrm{M}^{2} \sim 1.05$ - the first time $>1 \mathrm{~W}$ has been generated in TEM $_{00}$ mode from a diode-pumped Alexandrite laser. The slope efficiency was $44.2 \%$.

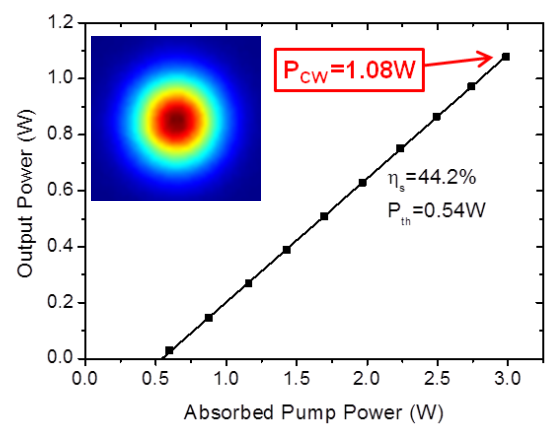

Fig. 2. Fibre-delivered diode end-pumping Alexandrite rod laser output power $(1.08 \mathrm{~W})$, slope efficiency $44.2 \%$ and $\mathrm{TEM}_{00}$ mode $\mathrm{M}^{2}=1.05$.

Using the extended cavity configuration wavelength tuning was achieved with a birefringent filter across $735-800 \mathrm{~nm}$. The short wavelength limit was mainly caused by the spectral shape of the output coupler mirror.

\section{B. High-Power Diode End-Pumped Alexandrite}

Much higher end-pumping was achieved with a $\sim 70 \mathrm{~W}$ free-space delivered red diode pump module. Beam shaping to laser rod involved using cylindrical optics to get a circularized pump distribution. The output power for this system for a compact cavity configuration is shown in Fig. 3. The best output power $26.2 \mathrm{~W}$ and highest slope efficiency $49 \%$ was achieved with the 
output mirror reflectivity of $99 \%$ and smallest spot size $(210 \mu \mathrm{m})$. This power is twenty times higher than prior diode-pumped Alexandrite and is also the highest slope efficiency ever achieved. The slope efficiency as function of output coupler reflectivity does not match simple fourlevel laser theory. We have reason to explain this by pump excited state absorption and have made measurements and theory that support this.

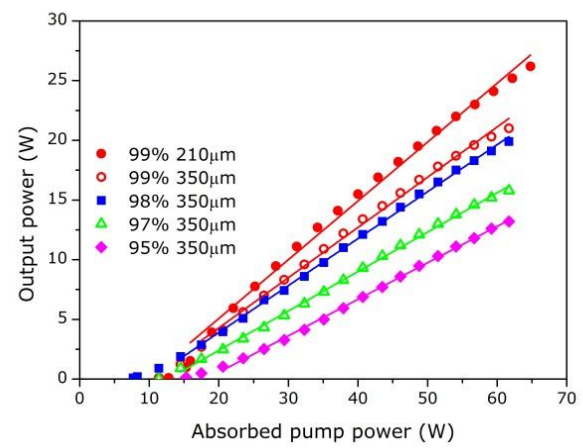

Fig. 3. Output power $(>26 \mathrm{~W})$ for end-pumped Alexandrite laser with high power free-space diode pumping module.

\section{High repetition rate $Q$-switched laser design}

For Q-switching a BBO Pockels cell was employed and the pump module was operated in pulsed mode with adjustable pump duration and repetition rate, as required. The cavity was designed for operation in $\mathrm{TEM}_{00}$ mode. Q-switched output energy against pump energy is shown in Fig. 4. A pulse energy $>1 \mathrm{~mJ}$ was achieved at $100 \mathrm{~Hz}$ pulse rate and slope efficiency approaching 20\%. Beam quality was $\mathrm{TEM}_{00}$, with $\mathrm{M}^{2} \sim 1.2$. Pulse energies $\sim 1 \mathrm{~mJ}$ were achieved up to $1 \mathrm{kHz}$ with some adjustment for thermal lensing effects and $\mathrm{TEM}_{00}$ operation maintained. Higher pulse energy results will be described using a dual-end-pumped laser configuration.

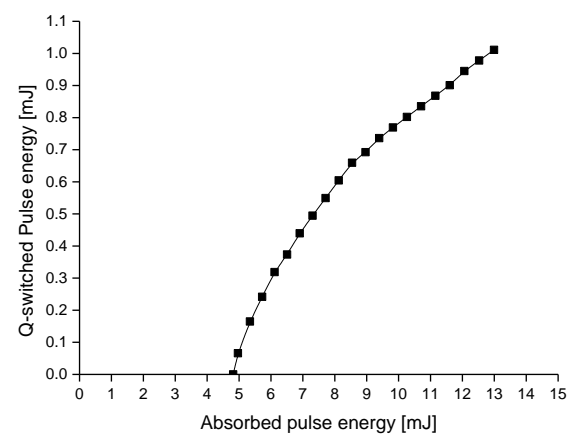

Fig. 4. Output pulse energy for Q-switched Alexandrite laser.

\section{DIODE SIDE-PUMPED ALEXANDRITE SLAB LASER SYSTEMS}

Side-pumped laser designs permit power scaling by the ability to add larger numbers of pumping modules, distribution of pump power, larger pumping volume and using a slab with increased options for thermal management by independent choice of slab crystal dimensions. Simple tranverse pump design and bounce geometry designs have been investigated

\section{A. Bounce Geometry Slab Laser Design}

In the bounce geometry [3] the laser mode takes a grazing incidence total internal reflection from the sidepump slab face as shown in the laser geometry of Fig. 5.

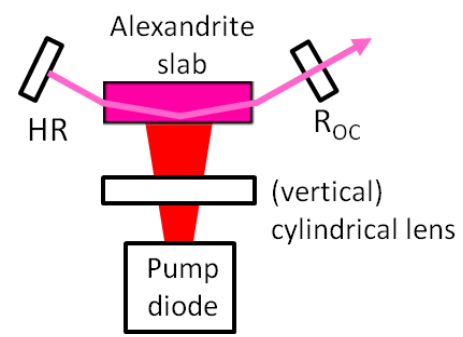

Fig. 5. Side-pumped bounce geometry Alexandrite laser design.

In this system greater than $12 \mathrm{~W}$ was achieved at a pump power $67 \mathrm{~W}$, as shown in Fig. 6. The figure shows that the output power (and hence efficiency) increase as the diode temperature is decreased. This correlates with the diode wavelength tuning to shorter wavelength, leading to higher pump absorption and increased extraction of the laser mode at the pump face.

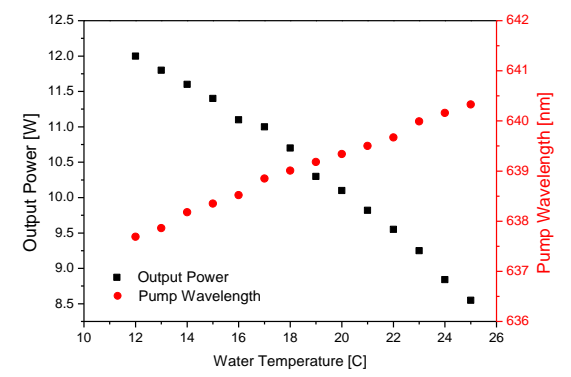

Fig. 6. Output power for bounce geometry Alexandrite slab laser and diode wavelength as function of diode temperature.

\section{Conclusions}

The breakthrough powers, efficiencies and high pulse rate Q-switch operation show that diode-pumped Alexandrite has attractive potential for tunable high power sources, including for remote sensing applications such as satellite-based lidar for Earth Observation. With further development diode-pumped Alexandrite might attain higher power (100W- or $\mathrm{kW}$-class) as well as compact femtosecond laser operation.

\section{ACKNOWLEDGMENT}

The authors acknowledge support from the European Space Agency for this work.

\section{REFERENCES}

[1] J. Walling et al, "Tunable Alexandrite lasers," IEEE J. Quant. Elec. 16, 1302-1315 (1980).

[2] A. Teppitaksak et al, "High efficiency $>26 \mathrm{~W}$ diode-endpumped Alexandrite laser”, Opt. Ex. 22, 16386 (2014).

[3] A. Minassian et al, "Ultra-high efficiency $\mathrm{TEM}_{00}$ diodeside-pumped Nd: $\mathrm{YVO}_{4}$ laser", Appl. Phys. B. 76, 341 (2004). 